\title{
Resistance of Bacteria to the Factors of the Innate Immune System, Mediated by Bacterial Proteases
}

\section{Tyurin YA $^{1,2^{*}}$ and Mustafin IG ${ }^{1}$}

${ }^{1}$ Kazan State Medical University, Republic of Tatarstan, Butlerov Street, 49, Russia

${ }^{2}$ Kazan Research Institute of Epidemiology and Microbiology, Kazan, Republic of Tatarstan, 420015, Big Red Street, 67, Russia

*Corresponding author: Yury A Tyurin, Kazan State Medical University, Republic of Tatarstan, Butlerov Street, 49, Russia, Tel: 8(843)2366791; E-mail: tyurin.yurii@yandex.ru

Received date: August 28, 2017; Accepted date: November 29, 2017; Published date: December 07, 2017

Copyright: (C2017 Tyurin YA, et al. This is an open-access article distributed under the terms of the Creative Commons Attribution License, which permits unrestricted use, distribution, and reproduction in any medium, provided the original author and source are credited.

\begin{abstract}
This analytical review presents the mechanisms used by opportunic pathogenic and obligate pathogenic bacteria to resist human innate immunity pressure. The main mechanisms of innate immune system and bacterial resistance are described. The main focus of this review is on the bacterial proteases involved in the resistance to the immune pressure.
\end{abstract}

Keywords: Bacterial proteases; Peptidase; Innate immunity; Pattern PRR receptors; Antimicrobial peptides; Chemokines; Cytokines

\section{Introduction}

Currently, database (www.ebi.ac.uk/merops/), contains data more than $9 \times 10^{5}$ peptidase. The MEROPS database uses a hierarchical, structure-based classification of the peptidases. Teach peptidase is assigned to a family on the basis of statistically significant similarities in amino acid sequence, and families that are thought to be homologous are grouped together in a clan. There is a summary page for each family and clan. Incises only $3614(0.4 \%)$ peptidases from them contains identifiers and in these 3614 , only $372(0.04 \%)$ are haws of both identifiers and EC number. Each peptidase is given a unique identifier known as a MEROPS ID. The MEROPS (ID) identifier consists of letters and members that reflects: the family identifier (three characters), a dot, and a three-digit number, e.g. S01.001. Peptidases from different organisms are assigned to a single ID when the available data indicates that they belong to the some catalytic type. Special forms of MEROPS ID are used for uncharacterized peptidases from model organisms, unassigned peptidases, non-peptidase homologues, pseudogenes and unsequenced peptidases.

All peptidases (proteolytic enzymes) are classified into MEROPS as nine catalytic types: aspartic peptidases, cysteine peptidases, Glupeptidases, metallo-peptidases, asparagine-peptidases, serinepeptidases, threonine peptidases, unclassifiable peptidases and unknown peptidases.

The most numerous catalytic group of these enzymes is the serine peptidase (family S). Currently, it includes almost 334,140 peptidases, of various organisms. Then follow cysteine peptidases (about 176844 enzymes) and metallo-peptidases (about 296030 enzymes). Each catalytic type forms a family of peptidases, homologous and highly orthologous proteins similar structure of these catalytic centers.

In this review, proteolytic enzymes from microorganisms are considered. Many of them are pathogenic or opportunistic pathogens for humans. All these enzymes belong to the following catalytic types or families: family $\mathrm{A}$ (aspartic peptidases, clan $\mathrm{AA}, \mathrm{AE}, \mathrm{AC}, \mathrm{AF}, \mathrm{AD}$ ), family $\mathrm{C}$ (cysteine peptidases, clan $\mathrm{CA}, \mathrm{CD}, \mathrm{CM}, \mathrm{CF}, \mathrm{CO}, \mathrm{CP}, \mathrm{CQ}$ ), as well as the family M (metallo-peptidases, clan MA, ME, MC, MD, MG, $\mathrm{MM}$ ) and family S (serine-peptidases, clan PA, PB, SE, PC, SF, SJ).

\section{Components of the Innate Immune System as Targets of Microbial Peptides}

The Innate immunity is conceptually defined as the body's ability to neutralize the alien and potentially dangerous biomaterial (microorganisms, transplants, toxins, tumor cells and virus-infected cells). This system induces the cellular part (phagocyte system and less specialized cells) and the humoral innate immunity (represented by the main bactericidal components contained in the body fluids providing the so-called "chemical protection" from microorganisms, as well as the system of contact activation of blood coagulation, the complement system and fibrinolysis). An important component of innate immunity is the normal microflora protecting agains patohogenic microflora $[1,2]$.

According to modern data, the magnitude of this component is very significant. In the biotopes of the skin and mucous membranes, there are about $10^{14}$ microorganisms belonging to commensals (normal microflora), their number, as a rule, exceeds the number of human cells several times [3].

Innate immunity active in skin is formed by the combined action of several systems. Firstly, it is a layer of keratinized skin epithelium, providing a waterproof physical barrier that limits the access of microorganisms to the underlying tissues. This physical barrier is strengthened by the so-called components of a chemical defense system consisting of antimicrobial peptides (such as cathelicidins, $\beta$ defensin, dermcidin, psoriasin, etc.) [4]. One of the key roles in chemical skin protection is played by fatty acids secreted by the sebaceous glands. The activity of these components in the skin significantly depends on its integrity. Different types of mucous membranes are impermeable to bacteria. The secrets of skin glands contain a wide range of antimicrobial peptides (AMP) and proteins that inhibit adhesion and invasion of microorganisms [5]. 
In addition, the antimicrobial protection of mucous membranes is enhanced by a complex lymphoid tissue associated with the mucosa (MALT, Mucosa-associated lymphoid tissue), which is rich in immunocompetent cells that coordinate the functions of both the innate and acquired immune system. How does of innate immunity react to microorganisms?

The destruction of the skin protection barrier, mucous and introduction of pathogenic microorganisms is recognized by innate immunity using PRRs (PRRs-pattern recognition receptors). These receptors have a high affinity for conserved microbial molecular fragments, characteristic for a wide range of microorganisms (peptidoglycan, lipopolysaccharide, lipoteichoic acids, lipoproteins, CpG DNA, flagellin, $\beta$-glucan, etc.) and other pathogen-associated molecular components (PAMPs-pathogen-associated molecular patterns) [6].

The PRRs are represented in the body in three forms: soluble forms (e.g., lipopolysaccharide binding protein, C-reactive protein, mannosebinding lectin, surfactant proteins $\mathrm{A}$ and $\mathrm{D}$ ); cellular receptors and opsonizing molecules (Toll-like receptors or TLRs, CD14); cytoplasmic receptors (e. g, NOD-like receptors). The main function of PRRs is to activate intracellular signaling pathways that trigger the expression of pro-inflammatory cytokines, chemokines, and antibacterial soluble effector molecules.

In addition, the body has in its arsenal a powerful complement system, activation of which is an essential part of the innate mechanisms of antimicrobial protection, realized by anaphylotoxins (C3a, C3b). Chemokines and anaphylotoxins attract neutrophils from the bloodstream and activate their bactericidal activity. All these processes initiate acute inflammation, which is absolutely necessary for the effective elimination of microorganisms. It should be noted that monocytes/macrophages, neutrophils, NK cells constitute effector cells of innate immunity. Neutrophils after the killing of microorganisms undergo apoptotic death. Macrophages are able to survive a longer period and participate in resolving the inflammatory reaction. In addition to the classical components of innate immune response in human, a system of contact activation of blood coagulation plays a significant role in the formation of resistance to microbial infection $[7,8]$. It is generally recognized that the system of contact activation of blood coagulation is one of the recognizing subsystems of innate immunity [9]. The so-called receptors activated by proteases (PARsprotease-activated receptors) represent another direct link between the system of contact activation of blood coagulation and innate immunity. Typically, these receptors are expressed on epithelial, endothelial cells, as well as on leukocytes and platelets. They are activated by proteases of the blood coagulation system, which are mediators of the innate immune response. The PARs regulate various functions of leukocytes, participate in the activation of proinflammatory intracellular signaling systems. Thus, PARs are considered as an integral part of the antimicrobial signaling defense system of the organism [10,11]. Similar functions have bolen found for epithelial integrin receptors [12]. Despite the formed of innate immune response, some bacteria acquired and developed the ways of inactivating the defense mechanisms.

Bacteria have a whole spectrum of virulent properties that include and allow them to survive when interacting with the immune system of innate immune complex mechanism of proteolytic activity. The main goal of pathogenic bacteria proteolytic enzymes is the signal and effector molecules of immune defense. We identified the main strategic directions developed by the bacteria to suppress the most ancient system of body protection, namely is innate immunity:

1) Effects on the complement system and fibrinolysis processes

2) Disruption of the activation of the coagulation contact system blood

3) The interaction between cytokines and their receptors

4) Inactivation of antimicrobial peptides (AMP), chemokines and cytokines

5) Action on recognition receptors (receptors activated by proteases, PRRs-receptors)

6) Exposure to phagocytes and suppression of phagocytic reactions

7) Development of proteolytic systems of capture and assimilation of the heme and free iron of the organism

8) Influence on intracellular signaling pathways of immunocompetent cells.

\section{Effects on the Complement System and Fibrinolysis}

The complement system is an integral and vital part of the innate and acquired immune system. This system can be activated by three ways: the classic way of complement activation (antigen-antibodydependent); lectin pathway molecules; an alternative way to activate complement (via binding of $\mathrm{C} 3$ to the surface of microorganisms). Pathogenic microorganisms have acquired the ability to destroy and bind components of complement to prevent their activation along appropriate paths.

The main targets of most bacterial proteases are C3 and C5 convertase complexes, in particular C3-protein and its activated forms, which are integral components of the $\mathrm{C} 5$-convertase complex. The cysteine protease (streptopain, SpeB, EC 3.4.22.10) of Streptococcus pyogenes cleaves the $\mathrm{C} 3$-component, preventing the formation of the C5-convertase complex, membrane-attack complex (MAC) and proinflammatory mediator-C5a [13]. The final effect leads to inhibition of both opsonization of bacteria and phagocytosis by neutrophils. Bacterial Streptopain also cleaves the properdin, forming the C5convertase complex after the alternative complement activation [14]. It was found that the majority of Streptococcus $s p$. Produces C5apeptidases from the family of the subtilisin serine proteases S.08.20 that cleave $\mathrm{C} 5 \mathrm{a}$ in its $\mathrm{N}$-terminal region and inhibit phagocytic clearance of microorganisms [15]. The protease PgtE (protein E, outer membrane protease E, EC 3.4.23.-, family A26.004) from Salmonella enterica cleaves several components of the complement system C3b, $\mathrm{C} 4 \mathrm{~b}$ and $\mathrm{C} 5$, affecting the activation of the convertase complex, which protect is bacteria from the action of complement [16]. Cysteine proteinase, StcE (family M 66.001), isolated from Escherichia coli O157: H7, cleaves the serpin C1 esterase inhibitor (C1-INH), a major regulator of the classical complement cascade $[17,18]$. These data suggest that by recruiting C1-INH to cell surfaces, StcE may protect both Escherichia coli O157:H7 and the host cells to which the bacterium adheres from complement-mediated lysis and potentially damaging inflammatory events [19].

\section{Effects on the Processes of Fibrinolysis}

Inflammatory response to bacterial infection leads to local thrombosis and blockade of the microcirculation system, which is an important mechanism to limit bacterial infection spread in tissues. 
Bacterial to escape this response on plasmin (plasminogen) affect as, the most potent endogenous protease present in the serum. Thus, by affecting the fibrinolysis system, many pathogenic bacteria are easily disseminated and avoid elimination [20]. The spirochete Borrelia burgdorferi, responsible for the development of Lyme disease, change the system of plasmin activators [21].

Various bacterial species, including Streptococcus sp., and Staphylococcus sp. expresses specific plasminogen activators [22]. In contrast, streptokinase and staphylokinase, use plasminogen nonproteolytic activators. Some types of bacterial plasminogen activators are effective working in a similar way and causing effects as activators tPA, uPA host organism. Some gram-negative bacteria, including Yersinia sp., Shigella sp. (SopA), Salmonella sp. (OmpE, PgtE), Vibrio fisheri, Legionella pneumophila, Escherichia coli (OmpT), Enterobacter sp., Mesorhizobium sp., Erwinia sp., and Agrobacter tumefatsiens express plasminogen activators that belong to the family A23-A26. The Omptin proteins (family A26.001) and represent aspartyl dependent protease, integrated into the outer membrane of bacterial cells [23]. Peptidase Pla (family A26) as one of the representatives of proteins of this family, from Yersinia pestis, is able not only to activate plasminogen, but also to inactivate $\alpha 2$-antiplasmin, an important plasmin inhibitor. A number of studies have shown the essential role of this enzyme for lymphogenous and hematogenous dissemination of Yersinia pestis [24].

\section{Inhibition of Contact Activation of Coagulation by Bacterial Proteases}

Activation of the blood coagulation system from contact with the bacterial cell surface leads to the generation of bactericidal peptides (kininogens, bradykinins), and stimulates the migration of macrophages. Bradykinins and their metabolites, in particular DesArg9BK, are inflammatory mediators that cause hypotension, increase vascular permeability, swelling, fever, and pain in the inflammatory focus [25]. Such bacteria as Staphylococcus aureus, Streptococcus pyogenes, Streptomyces caespitosus, Porphyromonas gingivalis, express proteases (staphopain A, B, family C47; streptopain, family C10; gingipaines-RgpA, RgpB, family C 25), that release kinins from kininogens or activate factors of contact systems of blood clotting (factor XII, plasma prokallikrein) [6]. The kinins increase the vascular permeability, and release of the main plasma components to the inflammatory focus, thereby enriching the nutrients and growth factors of the bacteria. The latter contributes to bacteria survival and dissemination [26].

Immunocompetent cells interacts using small proteins, called cytokines. Bacteria can block the signal function of cytokines by proteolytic modification of their molecules and/or their cellular receptors. It is not surprising that cytokines and their receptors are the main molecular targets of a whole spectrum of bacterial proteases.

\section{Inactivation of Antimicrobial Peptides (AMP)}

In humans, AMPs exhibit a wide range of activity. Beside killing bacteria they have immunostimulating, immunomodulating functions [27]. The mechanism of action of AMP is based on the destruction of the bacterial cell membrane integrity. Defensins and cathelicidins can potentiate the effects of other AMPs formed from chemokines, kininogen, heparin-binding protein, growth factors and other proteins $[28,29,30]$. Heaver bacteria developed a number of ways to avoid AMP [31]. AMPs are relatively resistant to proteolytic degradation several pathogenic bacterial species form proteases that cleave and inactivate AMP. Human cathelicidin LL-37 is a direct target for digestion by the enzyme streptopain (family C10, EC 3.4.22.10) of Streptococcus pyogenes, elastase B (family M04.005) of Pseudomonas aeruginosa, gelatinase (coccolysin, family M04.007) of Enterococcus feacalis and metalloprotease (ZapA, family M 10.057, clan MA) of Proteus mirabilis [32]. Inactivation of LL-37 with bacterial proteases underlies the pathogenesis of the development of chronic ulcerative skin and mucosal defects, etiologically associated with infection of Pseudomonas aeruginosa, Enterococcus feacalis and Proteus mirabilis [33]. It should be noted that the ZapA metalloprotease of Proteus mirabilis is a necessary virulence factor of uropathogenic strains isolated from patients with a urinary tract infection [34]. This protease inactivates LL-37, and $\beta$-defensin (hBD1), that contribut to the antibacterial protection the urinary system. Decreased activity of hBD1 is one of the factors that facilitate the colonization Proteus sp. [35]. A similar scenario exists in Porphyromonas gingivalis, the main etiological agent of human periodontitis, with respect to the bactericidal activity of AMP from saliva and parodontal tissues. Gingipaines from these bacteria split several different AMP including LL-37, dermaseptin, histatin 5, cecropin, brevinin, a-defensin (HNP-1), hBD-1, hBD-2, hBD3 [36]. Local deficiency of LL-37 due to their proteolytic degradation, creates favorable conditions for the development of severe forms of periodontitis [37]. Catelicidin provides an innate immune defense of the skin against bacterial infections caused by gram-positive cocci (Staphylococcus aureus, Streptococcus pyogenes) [38]. Proteases of these species are capable of cleavage cathelicidins thus aureolysin (family M4.009) Staphylococcus aureus ensures the inactivation of LL-37 in tissues infected with Staphylococcus sp. [39]. In addition, Staphylococcus aureus forms cysteine proteinases (staphopaines) that effectively inactivate tissue cystatins, which leads to an increase in the activity of tissue cathepsins in the inflammatory focus and rapid inactivation of AMP [40]. The gram-negative bacteria have a special system of enzymes of the family A26 peptidase (Omptin, Protease 7, EC 3.4.23.49, family A26.001), localized in the outer membrane, which are also able to effectively inactivate AMP [41]. Serine proteases, omptin, PgtE which is isolated from Salmonella enterica, cleaves $a$-helical cationic AMP, including LL-34, but does not inactivate protegrin or HNP-1 [42]. These data indicate that different omptin enzymes have certain specificity for AMP. The PgtE expression is regulated by the Fop/PhoQ sensitive microbial cell system that reacts to sublethal concentrations of cationic AMPs and through the degradation of these peptides, the Gramnegative bacteria proteases contribute to the survival of these bacteria in the human body [43].

\section{Activation and Inactivation of Various Cellular Receptors by Bacterial Proteases}

Receptors that are activated by proteases (PARs), refer to the subfamily of dual G-protein receptors, composed of seven transmembrane domains, which are activated by endogenous proteases [44]. Receptors, activated by proteases, under physiological conditions are normally activated by endogenous serine proteases. These receptors are expressed on platelets, endothelium, myocytes, T-lymphocytes and neurons. In humans, there are four types of receptors belonging to this family, PAR-1, 3, and 4 are activated by thrombin in physiological conditions, whereas PAR-2 can be activated by other proteolytic enzymes. Activation of PAR-2 leads to the formation of a proinflammatory response. Arginine-specific protease gingipain from Porphyromonas gingivalis is able to activate PAR-2 in neutrophils, 
Page 4 of 7

epithelial cells, resulting in the production of IL-6 in the site of infection $[45,46]$. The ability of this enzyme to activate PAR-1, 4 on platelets is also shown, leading to aggregation and microthrombosis in the infection site [47]. Number of have shown studies, that mice, deficient in the expression of PAR-2 receptors, were not affected by the development of periodontitis. Thus, a significant role of this type of receptors in the pathogenesis of the inflammatory reaction of the paradont in humans has been established [48].

Protease LepA (family S26.UNW), from by Streptococcus pyogenes activates NF- $\mathrm{BB}$ signaling pathway, through the activation of PAR-1, 2, 4-receptors and metallo-protease. Metalloprotease LasB (family M04.005) of Pseudomonas aeruginosa can destroy the extracellular domains of PAR-2 receptor and inactivate it [49]. The serralysin (family M10.051) of Serratia marcescens was able to activate PAR-2 receptor in carcinoma of the airways and HeLa cells lines, with subsequent activation of pro-inflammatory signaling pathways experimental cells [50]. The same ability to activate this type of receptor on epithelial cells of the stomach is set to proteases from Helicobacter pylori, which resulted in the increased production of proinflammatory IL- 8 in the centers of colonization of this bacterium.

\section{Effects on Chemokines}

Chemokines are a superfamily of cytokines-small proteins (8-25 $\mathrm{kDa})$. One group of chemokines stimulates the migration of immune cells to the site of infection. Another group regulates the processes of growth, maintenance of homeostasis and controls the development and differentiation of body tissues. About 50 chemokines have been found. Chemokine receptors are transmembrane proteins or G-protein coupled receptors (serpentine receptors, GPCR). Modulation of chemokine activity by partial proteolysis with matrix metalloproteases is one of the main mechanisms mediating the migration of phagocytes to the inflammatory focus [51]. Bacterial proteases, with specificity to chemokine IL- 8 was first described in Porphyromonas gingivalis. Thse proteases are a group of gingipaines (RgpA, RgpB, Kgp, family C 25.001-C25.003) that being soluble increase the activity of IL-8 in tissues, thereby contributing to the massive infiltration by neutrophils into the site infected paradont. The bacterial cell associated on the contrary inactivate IL- 8 by splitting it in several places of the polypeptide chain [52]. The Elastase B from Pseudomonas aeruginosa effectively destroys human CCL5 (RANTES), MCP-1 from monocytes, ENA-78, thereby violating the chemotaxis of T-lymphocytes, eosinophils and basophils. The degradation of chemokines by Pseudomonas aeruginosa proteases makes a significant contribution to the metabolism of chemokines in the respiratory tract and thus contributes to the chronicization of the inflammatory process the lung [53]. SpyCEP peptidase (cell envelope protease, family A S08.027) of Streptococcus pyogenes, can cleave the C-terminal domain of mouse chemokines of the group CXC and MIP-2. The ability to cleave IL- 8 by SpyCEP peptidase Streptococcus pyogenes is one of the mechanisms of inhibiting migration and suppressing the neutrophilic phagocytosis of these bacteria [54]. In addition, the ability to cleave GCP-2 (granulocyte chemotactic protein 2) and oncogenic growth factor alpha (GRO- $\alpha$ ) of the main chemokines present in the human tonsils has been demonstrated for SpyCEP peptidase. The cleavage of GCP-2 and GRO- $\alpha$ by the SpyCEP peptidase nullifies their ability to primarily activate neutrophils, adversely affecting the innate immune response [55]. All these data together suggest that the SpyCEP peptidase is a very effective "weapon" used by Streptococcus $s p$. to suppress the phagocytic link in the innate immunity system [56].

\section{Bacterial Proteases Affect the Intracellular Signaling Pathways}

Binding of pathogens to PRPs-receptors leads to signal transmission to the cell and activation of several signaling intracellular systems. First of all, they are mitogen-activated protein kinase systems (MAPK, ERK, $\mathrm{NK}$ and p38) and the signal pathway of the nuclear transcription factor $\kappa \mathrm{B}(\mathrm{NF}-\kappa \mathrm{B})$, which regulate the production of pro-inflammatory cytokines, and the responses of innate immunity, including mobilization of neutrophils, activation of macrophages and isolation of bactericidal effector molecules. The signal transfer cascade is feedbackregulated by a covalent modification of some intracellular factors: either by phosphorylation or by binding to SUMO-proteins that perform functions of modulators of intracellular enzymes. Some bacteria have the acquired ability to destroy modulators of these signaling pathways, by introducing into the host cells specific bacterial proteases that activate cell isopeptidases. Ultimately, there is a disruption in the transmission of the intracellular signal, which leads to apoptotic cell death. It is this survival strategy that demonstrates the pathogenic strains of Yersinia sp. (Yersinia pestis, Yersinia pseudotuberculosis, Yersinia enterocolitica). Injection of enzymes into host cells in all pathogenic strains of Yersinia sp. is carried out by type III secretory system (T3SS), whose proteins are encoded by the plasmid genome. The T3SS system includes the YopJ (family C55.001), which has high homology with the cysteine protease (clan CE) [57,58]. Enzymes homologous to YopJ from Yersinia enterocolitica (YopP) are capable of disrupting the intracellular signaling pathways responsible for the cell-producing transmitters of interferon, NF-kB, and MAPK systems $[59,60,61]$.

Recently, it has been found that YopJ (family C55.001) is capable of exhibiting acetyltransferase activity; it is suggested that YopJ/P acetylates the MMPK kinase (MKK6, MEK2) of host cells, which blocks their subsequent phosphorylation and activation [62,63]. Along with YopJ-like enzymes, other species of Gram-negative pathogenic bacteria form proteins related to Ubl-specific proteases (ubiquitinspecific) of the C48 family; for example, SseL peptidase (family C79) isolated from Salmonella enterica, suppresses intracellular degradation of I $\kappa B$ and, thus, inhibits the activation of NFkB [64]. Similar ChlaDub peptidases expressed in Chlamydia trachomatis and protease ElaD of Escherichia coli have similar activity $[65,66]$. It is significant that ChlaDub peptidase 1, 2 (CT868, CT867 peptidase, family C48.032, C48.033) and ElaD (family C79.001) are expressed only in pathogenic bacterial species [67]. Also, enzymes that affect modulators of intracellular signaling systems include cysteine peptidase YopT (family C58.001) from Yesinia pestis and Pseudomonas syringae (AvrPphB peptidase, family C58.002). The YopT enzyme cleaves the intracellular factors RhoA, Rac, and Cdc42 of GTPase in the host cells, thereby disrupting the actin polymerization and eventually disrupting the cell cytoskeleton [68]. On the example of macrophages-this leads to a loss of ability to phagocytize bacteria. Similarly, the intracellular GTPase and serine/threonine kinases in plant cells have the bacterial enzyme AvrPphB peptidase (family C58.002, clan CA) isolated from Pseudomonas syringae [69,70]. In contrast to the enzymes described above, which are introduced directly through the membrane into the host cell, the toxin from Bacillus anthracis enters the cell only with endocytosis, after which it moves from the endosomes to the cytoplasm and its metalloproteinase component, related to the lethal toxin cleaves the MKK kinases, thereby effectively blocking the activation of a genes, dependent on the NF-kB factor [71]. 


\section{Effects on Phagocytes}

Bacterial proteases are able to accelerate the premature apoptotic death of phagocytes, or are capable of inactivating their bactericidal activity. The very specific mechanisms of these processes are the manipulation of a cascade of modulators involved in intracellular signaling metabolic pathways [72]. In addition, the ability of selective proteolysis of antibodies in the "hinge" region has been is shown for streptopain (SpeB, erythrotoxin B, family C10.001) [73]. Thus, in vivo SpeB contributes to the intracellular survival of Streptococcus pyogenes in macrophages, as well as aureolysin (SepP1 g.p. Staphylococcus aureus, family M04.009) for the survival of Staphylococcus aureus in phagocytes [74]. Another mechanism used by bacteria for modify phagocytes is the proteolytic modification of specific receptors on their surface. The ability of bacterial proteases to induce cleavage cytokine receptors, for example, C5aR, as well as CD14, CD31, CD44, syndecan-1R and the urokinase-like plasminogen activator receptor has been shout [75]. The Staphylococcus aureus the mechanism of selective cleavage of $\mathrm{CD} 11 \mathrm{~b}$ on phagocytes by staphopain B (SspB, family C47.002), cysteine proteinase, that provides effective elimination phagocytes [76]. Similar effects on CD31 receptor on neutrophils have protease (gingipain, RgpB, family C25.003) from Porphyromonas gingivalis [77,78].

\section{Final Consideration}

Thus, in the course of their evolution, the bacteria acquired a whole system of specialized enzymes proteases that effectively affect various components of the host innate immune system. The further study of these enzymes will allow us to develop etiotropic agents for treating bacterial infections, as well as specific prevention and therapeutic approaches. It should be noted that an example of such an approach was the creation of a whole group of HIV protease inhibitors that are successfully used in the treatment of HIV infection.

\section{Conflicts of Interest}

The authors declare no conflicts of interest.

\section{References}

1. Mshvildadze M, Neu J (2010) The infant intestinal microbiome: friend or foe? Early Hum Dev 1: 67-71.

2. Gallo RL, Hooper LV (2012) Epithelial antimicrobial defence of the skin and intestine. Nat Rev Immunol 12: 503-516.

3. Suárez JE (2015) Autochthonous microbiota, probiotics and prebiotics. Nutr Hosp 1: 3-9.

4. Menzies BE, Kenoyer A (2006) Signal transduction and nuclear responses in Staphylococcus aureus-induced expression of human b-defensin 3 in skin keratinocytes. Infect Immun 74: 6847-6854.

5. Yeaman MR, Bayer AS (2006) Antimicrobial peptides versus invasive infections. Curr Top Microbiol Immunol 306: 111-152.

6. Haitov RM (2014) Mehanizmyi vrozhdyonnogo immuniteta. V Knige: Immunologiya: struktura i funktsii immunoy sistemyi: uchebnoe posobie/RM Haitov-Moscow: GEOTAR-Media S: 33-36.

7. Esmon CT (2004) Interactions between the innate immune and blood coagulation systems. Trends Immunol 25: 536-542.

8. Zubairov DM (2000) Molekulyarnyie osnovyi svertyivaniya krovi i trombobrazovaniya. Kazan FEN S: 367.

9. Frick IM, Björck L, Herwald H (2007) The dual role of the contact system in bacterial infectious disease. Thromb Haemost 98: 497-502.
10. Shpacovitch V, Feld M, Bunnett NW, Steinhoff M (2007) Proteaseactivated receptors: novel PARtners in innate immunity. Trends Immunol 28: 541-550.

11. Madanan MG, Mechoor A (2017) Detection and characterization of bacterial proteinases using zymography. Methods Mol Biol 1626: 103-104.

12. Ulanova M, Gravelle S, Barnes R (2009) The role of epithelial receptors in recognition of pulmonary pathogens. J Innate Immun 1: 145-156.

13. Terao Y, Mori Y, Yamaguchi M, Shimizu Y, Ooe K, et al. (2008) Group A streptococcal cysteine protease degrades $\mathrm{C} 3(\mathrm{C} 3 \mathrm{~b})$ and contributes to evasion of innate immunity. J Biol Chem 283: 6253-6260.

14. Tsao N, Tsai WH, Lin YS, Chuang WJ, Wang CH, et al. (2006) Streptococcal pyrogenic exotoxin B cleaves properdin and inhibits complement-mediated opsonophagocytosis. Biochem Biophys Res Commun 339: 779-784.

15. Shet A, Kaplan E, Johnson D, Cleary PP (2004) Human immunogenicity studies on group A streptococcal C5a peptidase (SCPA) as a potential vaccine against group A streptococcal infections. Indian J Med Res 119: 95-98.

16. Ramu P, Tanskanen R, Holmberg M, Lähteenmäki K, Korhonen TK, et al. (2007) The surface protease PgtE of Salmonella enterica affects complement activity by proteolytically cleaving C3b, C4b and C5. FEBS Lett 581: 1716-1720.

17. Lathem WW, Grys TE, Witowski SE, Torres AG, Kaper JB (2002) StcE, a metalloprotease secreted by Escherichia coli O157:H7, specifically cleaves C1 esterase inhibitor. Mol Microbiol 45: 277-288.

18. Grys TE, Walters LL, Welch RA (2006) Characterization of the StcE protease activity of Escherichia coli O157:H7. J Bacteriol 188: 4646-4653.

19. Lathem WW, Bergsbaken T, Welch RA (2004) Potentiation of C1 esterase inhibitor by StcE, a metalloprotease secreted by Escherichia coli O157:H7. J Exp Med 199: 1077-1087.

20. Sanderson-Smith ML, Dinkla K, Cole JN, Cork AJ, Maamary PG, et al. (2008) M protein-mediated plasminogen binding is essential for the virulence of an invasive Streptococcus pyogenes isolate. FASEB J 22: 2715-2722.

21. Coleman JL, Gebbia JA, Piesman J, Degen JL, Bugge TH, et al. (1997) Plasminogen is required for efficient dissemination of $\mathrm{B}$. burgdorferi in ticks and for enhancement of spirochetemia in mice. Cell 89: 1111-1119.

22. Ward PN, Abu-Median AB, Leigh JA (2008) Structural consideration of the formation of the activation complex between the staphylokinase-like streptococcal plasminogen activator PadA and bovine plasminogen. J Mol Biol 381: 734-747.

23. Haiko J, Suomalainen M, Ojala T, Lähteenmäki K, Korhonen TK (2009) Invited review: Breaking barriers--attack on innate immune defences by omptin surface proteases of enterobacterial pathogens. Innate Immun 15: 67-80.

24. Sebbane F, Jarrett CO, Gardner D, Long D, Hinnebusch BJ (2006) Role of the Yersinia pestis plasminogen activator in the incidence of distinct septicemic and bubonic forms of flea-borne plague. Proc Natl Acad Sci USA 103: 5526-5530.

25. Bengtson SH, Sandén C, Mörgelin M, Marx PF, Olin AI (2009) Activation of TAFI on the surface of Streptococcus pyogenes evokes inflammatory reactions by modulating the kallikrein/kinin system. J Innate Immun 1: 18-28.

26. Hu SW, Huang CH, Huang HC, Lai YY, Lin YY (2006) Transvascular dissemination of Porphyromonas gingivalis from a sequestered site is dependent upon activation of the kallikrein/kinin pathway. J Periodontal Res 41: 200-207.

27. Yang D, Liu ZH, Tewary P, Chen Q, de la Rosa G, et al. (2007) Defensin participation in innate and adaptive immunity. Curr Pharm Des 13: 3131-3139.

28. Eliasson M, Egesten A (2008) Antibacterial chemokines--actors in both innate and adaptive immunity. Contrib Microbiol 15: 101-117.

29. Frick IM, Akesson P, Herwald H, Mörgelin M, Malmsten M, et al. (2006) The contact system--a novel branch of innate immunity generating antibacterial peptides. EMBO J 25: 5569-5578. 
30. Malmsten M, Davoudi M, Walse B, Rydengård V, Pasupuleti M (2006) Antimicrobial peptides derived from growth factors. Growth Factors 25: 60-70.

31. Nizet V (2006) Antimicrobial peptide resistance mechanisms of human bacterial pathogens. Curr Issues Mol Biol 8: 11-26.

32. Steck N, Hoffmann M, Sava IG, Kim SC, Hahne H, et al. (2011) Enterococcus faecalis metalloprotease compromises epithelial barrier and contributes to intestinal inflammation. Gastroenterology 141: 959-971.

33. Park PW, Pier GB, Preston MJ, Goldberger O, Fitzgerald ML, et al. Syndecan-1 shedding is enhanced by LasA, a secreted virulence factor of Pseudomonas aeruginosa. J Biol Chem 275:3057-3064.

34. Glushko Yu A, Safina NA, Tyurin Yu A, Zinkevich OD (2004) Spektr i aktivnost Ig-proteinaz mochi kak marker hronicheskogo pielonefrita. Terapevticheskiy arhiv 76: 43-45.

35. Belas R, Manos J, Suvanasuthi R (2004) Proteus mirabilis ZapA metalloprotease degrades a broad spectrum of substrates, including antimicrobial peptides. Infect Immun 72: 5159-5167.

36. Carlisle MD, Srikantha RN, Brogden KA (2009) Degradation of $\alpha$ - and $\beta$ defensins by culture supernatants of Porphyromonas gingivalis strain 381 . J Innate Immun 1: 367-380.

37. Puklo M, Guentsch A, Hiemstra PS, Eick S, Potempa J (2008) Analysis of neutrophil-derived antimicrobial peptides in gingival crevicular fluid suggests importance of cathelicidin LL-37 in the innate immune response against periodontogenic bacteria. Oral Microbiol Immunol 23: 328-335.

38. Johansson L, Thulin P, Sendi P, Hertzén E, Linder A, et al. (2008) Cathelicidin LL-37 in severe Streptococcus pyogenes soft tissue infections in humans. Infect Immun 76: 3399-3404.

39. Lai Y, Villaruz AE, Li M, Cha DJ, Sturdevant DE, et al. (2007) The human anionic antimicrobial peptide dermcidin induces proteolytic defence mechanisms in staphylococci. Mol Microbiol 63: 497- 506.

40. Vincents B, Onnerfjord P, Gruca M, Potempa J, Abrahamson M (2007) Down-regulation of human extracellular cysteine protease inhibitors by the secreted staphylococcal cysteine proteases, staphopain A and B. Biol Chem 388: 437-446.

41. Hwang BY, Varadarajan N, Li H, Rodriguez S, Iverson BL, et al. (2007) Substrate specificity of the Escherichia coli outer membrane protease OmpP. J Bacteriol 189: 522-530.

42. Guina T, Yi EC, Wang H, Hackett M, Miller SI (2000) A PhoP-regulated outer membrane protease of Salmonella enterica serovar typhimurium promotes resistance to alpha-helical antimicrobial peptides. J Bacteriol 182: 4077-4086.

43. Bader MW, Navarre WW, Shiau W, Nikaido H, Frye JG, et al. (2003) Regulation of Salmonella typhimurium virulence gene expression by cationic antimicrobial peptides. Mol Microbiol 50: 219-230.

44. Rezaie AR (2014) Protease-activated receptor signalling by coagulation proteases in endothelial cells. Thromb Haemost 112: 876-882.

45. Lourbakos A, Yuan YP, Jenkins AL, Travis J, Andrade-Gordon P, et al. (2001) Activation of protease-activated receptors by gingipains from Porphyromonas gingivalis leads to platelet aggregation: a new trait in microbial pathogenicity. Blood 97: 3790-3797.

46. Lourbakos A, Potempa J, Travis J, D'Andrea MR, Andrade-Gordon P, et al. (2001) Arginine-specific protease from Porphyromonas gingivalis activates protease-activated receptors on human oral epithelial cells and induces interleukin-6 secretion. Infect Immun 69: 5121-5130.

47. Lourbakos A, Yuan YP, Jenkins AL, Travis J, Andrade-Gordon P, et al. (2001) Activation of protease-activated receptors by gingipains from Porphyromonas gingivalis leads to platelet aggregation: a new trait in microbial pathogenicity. Blood 97: 3790-3797.

48. Holzhausen M, Spolidorio LC, Ellen RP, Jobin MC, Steinhoff M, et al. (2006) Protease-activated receptor-2 activation: a major role in the pathogenesis of Porphyromonas gingivalis infection. Am J Pathol 168: 1189-1199.

49. Kida Y, Higashimoto Y, Inoue H, Shimizu T, Kuwano K (2008) A novel secreted protease from Pseudomonas aeruginosa activates NF-kappaB through protease-activated receptors. Cell Microbiol 10: 1491-1504.
50. Kida Y, Inoue H, Shimizu T, Kuwano K (2007) Serratia marcescens serralysin induces inflammatory responses through protease-activated receptor 2. Infect Immun 75: 164-174.

51. Mortier A, Gouwy M, Van Damme J, Proost P (2011) Effect of posttranslational processing on the in vitro and in vivo activity of chemokines. Exp Cell Res 10; 317: 642-654.

52. Mikolajczyk-Pawlinska J, Travis J, Potempa J (1998) Modulation of interleukin- 8 activity by gingipains from Porphyromonas gingivalis: implications for pathogenicity of periodontal disease. FEBS Lett 440: 282-286.

53. Leidal KG, Munson KL, Johnson MC, Denning GM (2003) Metalloproteases from Pseudomonas aeruginosa degrade human RANTES, MCP-1, and ENA-78. J Interferon Cytokine Res 23: 307-318.

54. Zinkernagel AS, Timmer AM, Pence MA, Locke JB, Buchanan JT, et al. (2008) The IL-8 protease SpyCEP/ScpC of group A Streptococcus promotes resistance to neutrophil killing. Cell Host Microbe 4: 170-178.

55. Kida Y, Higashimoto Y, Inoue H, Shimizu T, Kuwano K (2008) A novel secreted protease from Pseudomonas aeruginosa activates NF-kappaB through protease-activated receptors. Cell Microbiol 10: 1491-1504.

56. Wolf M, Albrecht S, Märki C (2008) Proteolytic processing of chemokines: implications in hysiological and pathological conditions. Int J Biochem Cell Biol 40: 1185-1198.

57. Orth K, Xu Z, Mudgett MB, Bao ZQ, Palmer LE, et al. (2000) Disruption of signaling by Yersinia effector YopJ, a ubiquitin-like protein protease. Science 290: 1594-1597.

58. Zhou H, Monack DM, Kayagaki N, Wertz I, Yin J, et al. (2005) Yersinia virulence factor YopJ acts as a deubiquitinase to inhibit NF-kappa B activation. J Exp Med 202: 1327-1332.

59. Thiefes A, Wolf A, Doerrie A, Grassl GA, Matsumoto K, et al. (2006) The Yersinia enterocolitica effector YopP inhibits host cell signalling by inactivating the protein kinase TAK1 in the IL-1 signalling pathway. EMBO Rep 7: 838-844.

60. Haase R, Richter K, Pfaffinger G, Courtois G, Ruckdeschel K (2005) Yersinia outer protein $\mathrm{P}$ suppresses TGF-beta-activated kinase-1 activity to impair innate immune signaling in Yersinia enterocoliticainfected cells. J Immunol 175: 8209-8217.

61. Sweet CR, Conlon J, Golenbock DT, Goguen J, Silverman N (2007) YopJ targets TRAF proteins to inhibit TLR-mediated NF-kappaB, MAPK and IRF3 signal transduction. Cell Microbiol 9: 2700-2715.

62. Mukherjee S, Keitany G, Li Y, Wang Y, Ball HL, et al. (2006) Yersinia YopJ acetylates and inhibits kinase activation by blocking phosphorylation. Science 312: 1211-1214.

63. Trosky JE, Liverman AD, Orth K (2008) Yersinia outer proteins: Yops. Cell Microbiol 10: 557-565.

64. Le Negrate G, Faustin B, Welsh K, Loeffler M, Krajewska M, et al. (2008) Salmonella secreted factor $\mathrm{L}$ deubiquitinase of Salmonella typhimurium inhibits NF-kappa B, suppresses I-kappa B-alpha ubiquitination and modulates innate immune responses. J Immunol 180: 5045-5056.

65. Misaghi S, Balsara ZR, Catic A, Spooner E, Ploegh HL, et al. (2006) Chlamydia trachomatisderived deubiquitinating enzymes in mammalian cells during infection. Mol Microbiol 61: 142-150.

66. Catic A, Misaghi S, Korbel GA, Ploegh HL (2008) ElaD, a Deubiquitinating protease expressed by E. coli. PLoS One 2: e381.

67. Chosed R, Tomchick DR, Brautigam CA, Mukherjee S, Negi VS, et al. (2007) Structural analysis of Xanthomonas XopD provides insights into substrate specificity of ubiquitin-like protein proteases. J Biol Chem 282: 6773-6782.

68. Shao F, Merritt PM, Bao Z, Innes RW, Dixon JE (2002) A Yersinia effector and a Pseudomonas avirulence protein define a family of cysteine proteases functioning in bacterial pathogenesis. Cell 109: 575-588.

69. Zhang J, Li W, Xiang T, Liu Z, Laluk K, et al. (2010) Receptor-like cytoplasmic kinases integrate signaling from multiple plant immune receptors and are targeted by a Pseudomonas syringae effector. Cell Host Microbe 7: 290-301. 
Citation: Tyurin YA, Mustafin IG (2017) Resistance of Bacteria to the Factors of the Innate Immune System, Mediated by Bacterial Proteases. J Immuno Biol 2: 134. doi:10.4172/2476-1966.1000134

Page 7 of 7

70. Russell AR, Ashfield T1, Innes RW (2015) Pseudomonas syringae effector AvrPphB suppresses AvrB-induced activation of RPM1, but not AvrRpm1-induced activation. Mol Plant Microbe Interact 28: 727-735.

71. Park JM, Greten FR, Li ZW, Karin M (2002) Macrophage apoptosis by anthrax lethal factor through p38 MAP kinase inhibition. Science 297: 2048-2051.

72. Chiang-Ni C, Wang CH, Tsai PJ, Chuang WJ, Lin YS, et al. (2006) Streptococcal pyrogenic exotoxin B causes mitochondria damage to polymorphonuclear cells preventing phagocytosis of group A streptococcus. Med Microbiol Immunol 195: 55-63.

73. Söderberg JJ, von Pawel-Rammingen U (2008) The streptococcal protease IdeS modulates bacterial IgG Fc binding and generates $1 / 2$ Fc fragments with the ability to prime polymorphonuclear leucocytes. Mol Immunol 45: 3347-3353.

74. Kubica M, Guzik K, Koziel J, Zarebski M, Richter W, et al. (2008) A potential new pathway for Staphylococcus aureus dissemination: the silent survival of S. aureus phagocytosed by human monocyte-derived macrophages. PLoS One 3: e1409.

75. Cichy J, Bals R, Potempa J, Mani A, Puré E (2002) Proteinase-mediated release of epithelial cell-associated CD44. Extracellular CD44 complexes with components of cellular matrices. J Biol Chem 277: 44440-44447.

76. Smagur J, Guzik K, Magiera L, Bzowska M, Gruca M, et al. (2009) A new pathway of staphylococcal pathogenesis: Apoptosis-like death induced by Staphopain B (SspB) in human peripheral blood neutrophils and monocytes. J Innate Immun 1: 456-478.

77. Guzik K, Bzowska M, Smagur J, Krupa O, Sieprawska M, et al. (2007) A new insight into phagocytosis of apoptotic cells: proteolytic enzymes divert the recognition and clearance of polymorphonuclear leukocytes by macrophages. Cell Death Differ 14: 171-182.

78. Fitzpatrick RE, Wijeyewickrema LC, Pike RN (2009) The gingipains: scissors and glue of the periodontal pathogen, Porphyromonas gingivalis. Future Microbiol 4: 471-487. 